\title{
Independent Control of Temperature and Humidity in Air Conditioners by Using Fuzzy Sliding Mode Approach
}

\author{
Lijian Yang, ${ }^{1,2}$ Ziyang Li, ${ }^{1,2}$ Zhengtian Wu $\mathbb{D}^{1,2}$ Mingyang Xie, ${ }^{3}$ Baoping Jiang, ${ }^{1,2}$ \\ and Baochuan Fu $\mathbb{D}^{1,2}$ \\ ${ }^{1}$ School of Electronic and Information Engineering, Suzhou University of Science and Technology, Suzhou, China \\ ${ }^{2}$ Suzhou Institute of Smart City, Suzhou University of Science and Technology, Suzhou, China \\ ${ }^{3}$ College of Automation Engineering, Nanjing University of Aeronautics \& Astronautics, Nanjing, China
}

Correspondence should be addressed to Zhengtian Wu; wzht8@mail.usts.edu.cn and Baochuan Fu; fubc@163.com

Received 17 June 2020; Accepted 18 July 2020; Published 4 August 2020

Academic Editor: Quanxin Zhu

Copyright (C) 2020 Lijian Yang et al. This is an open access article distributed under the Creative Commons Attribution License, which permits unrestricted use, distribution, and reproduction in any medium, provided the original work is properly cited.

This paper proposes a sliding mode control (SMC) strategy to solve the problem of independent control of temperature and humidity in air conditioners; the complexity increases due to the need to make full use of the wind side for cooling. First, dynamics of indoor temperature and humidity are determined based on mathematical models. Second, in order to reduce the chattering effect of SMC and coordinate indoor conditions to satisfy people's needs, the independent control of temperature and humidity is realized via a novel fuzzy sliding mode control strategy based on reaching laws. Finally, simulation results are provided to verify the effectiveness of the proposed method.

\section{Introduction}

In traditional central air-conditioning control systems, temperature is typically the controlled parameter and multiloop PID control method is commonly adopted. However, achieving desired control performance is difficult with the aid of traditional PID controllers due to a variety of reasons, for instance, nonlinearity and time-varying effects in temperature variation and complexity in establishing mathematical models [1]. In addition to the complexity of parameter setting methods, conventional PID controller parameters often have poor system performance and poor adaptability to the controlled process. Therefore, ordinary PID control is difficult to meet the control requirements in the central air-conditioning system.

Compared with the conventional air-conditioning system, the temperature- and humidity-independent control system uses high-temperature cold source, solution humidity control, and other technologies to ensure energy saving. Lazzarin and Castellotti studied a self-regenerating solution dehumidification system driven by a heat pump, which was applied to supermarket to verify its energy efficiency by simulating year-round outdoor working conditions [2]. Hao designed a cooling radiant roof, rotary dehumidification, and displacement ventilation air conditioner system. The system can effectively save electrical energy, significantly improve the indoor environment quality, and increase comfort [3]. Although the advantages of independent temperature and humidity controlled airconditioning systems are obvious, there are still some problems in the actual operation process. For example, if the temperature- and humidity-independent control system needs to make full use of the free cooling on the wind side during the transition season, the exhaust fan needs to be configured, which increases the complexity of the system [4]. Compared with traditional air-conditioning systems, the installation of temperature- and humidity-independent control air-conditioning is more stringent, complicated, and costly.

During air-conditioning control, the fuzzy control strategy is more efficient than the PID control because the former can adjust the room temperature under partial load operation and flow rate of cooling water in cooling coil shows satisfactory oscillation response; however, given that 
the fuzzy approach lacks systemicity, the disadvantages of using fuzzy control method alone in air-conditioning systems are instability and poor robustness in the fuzzy process [5, 6]. In [7-9], a genetic algorithm-based PID controller and self-tuning PID-type fuzzy adaptive controller were designed to simulate the temperature of central air-conditioning systems. These two methods can meet the needs of central air-conditioning temperature control system; the experimental results show that the cooling effect is better. For the problem of parameter/structure uncertainty and input dead zone of nonlinear system, an adaptive control method based on neural network is designed to ensure the stability and robustness of the system $[10,11]$. The articles [12-15] study the feedback control problem of stochastic nonlinear systems and have made a lot of contributions to the backstepping between controllers and the system stability proof. In order to compensate the interference or unmeasured state of the system, the articles $[16,17]$ give a new form of reduced-order K-filters. These control methods and anti-interference methods are also applicable to airconditioning systems with large lags and numerous interference.

Sliding mode control (SMC) was proposed by Emelyanov et al. in the 1950s. Itkin et al. subsequently summarized and developed SMC theory [18]. Later, sliding mode control was widely used in robotics and aviation [19]. Given that the sliding motion is designed to be independent of system parameters and disturbances, therefore, SMC models have the good properties of strong robustness, fast response, and easy implementation. These characteristics can be optimized in the central air-conditioning system and compensate for the shortcomings of conventional PID controllers. In addition, it has witnessed many researches in the related field; for example, a class of discrete-time interval type-2 fuzzy systems were studied in [20]. In [21], the problem of sliding mode control for semi-Markov switching systems with quantized measurement in finite-time level was investigated. When system state trajectory reached the sliding mode surface, the exclusive occurrence of sliding motion on the sliding surface toward the equilibrium point is impossible due to switching signals. Several studies have shown that the fuzzy SMC can suppress chattering effect by linearizing discontinuous signals. The fuzzy sliding mode approach reduces the influence of switching control and remarkably reduces the chattering effect [22]. In terms of application, the fuzzy SMC approach was applied to stochastic systems with (semi)Markov switching parameters which have been developed in [23-25]. In [26, 27], the fuzzy SMC was proposed for nonlinear descriptor systems. Therefore, this paper proposes fuzzy rules in the design of sliding mode parameters and reduction of chattering phenomenon of SMC to ensure the accurate control of indoor temperature and humidity.

Different from the traditional control method, the robust and fast response characteristics of the fuzzy sliding mode control adopted in this paper are more suitable for the airconditioning system with large lags and numerous interference. Meanwhile, the contribution of this study is to propose fuzzy rules in the design of sliding mode controller for independent control of indoor temperature and humidity to solve the problem of increased complexity due to the configuration of the exhaust fan. Compared with the conventional PID control and fuzzy PID control methods, the proposed fuzzy SMC strategy achieves faster adjustment response, smaller overshoot, higher accuracy, and better control effect. At the same time, it ensures that the indoor carbon dioxide concentration is at a normal level. However, this air-conditioning system is mainly suitable for the case where the room model data is known. The design method of the stochastic delay feedback control and the stability controller for the discrete-time half-Markov jump linear system with bounded residence time used in [28-30] will be of a great help for the future work of expanding to random cases.

\section{Mathematical Modeling of Indoor Environment}

The independent control of temperature and humidity in the air-conditioning system adjusts the volume of fresh air supply of the dehumidification system and the volume of return air supply of the temperature control system to meet people's requirements for indoor environment comfort [31]. The system is illustrated in Figure 1.

This study considers an office building environment with the following assumptions [32]: (1) the office building is considered as a closed-loop system. (2) The air pressure in the building remains unchanged. (3) The indoor air diffusion is good and the room temperature can be measured using a temperature sensor. (4) The effect of humidity on room temperature is unclear.

2.1. Dynamic Response of Temperature. Given that the independent control of temperature and humidity in the airconditioning system uses fresh air in the dehumidification system to remove indoor residual humidity, $\mathrm{CO}_{2}$, and odors such that to ensure indoor air quality, the dynamic response modeling of room temperature must only consider the room's sensible heat [33].

The heat energy balance in an air-conditioning system is expressed as follows [34, 35]:

$$
\dot{Q}_{s} t=Q_{r}(t)+Q_{w}(t)-Q_{d}(t),
$$

where $Q_{r}(t)$ is the heat provided by the air-conditioning supply air; $Q_{s} t$ is the sensible heat; $Q_{d}(t)$ is the outflow heat; and $Q_{w}(t)$ is the heat dissipation.

The room sensible heat change can be described as follows [28]:

$$
\dot{Q}_{s} t=\rho V C_{1} T_{i},
$$

where $\rho$ is the indoor air density, $\left(\mathrm{kg} / \mathrm{m}^{3}\right) ; V$ is the room volume, $\mathrm{m}^{3} ; C_{1}$ is the specific heat capacity of indoor air, $\mathrm{J} /$ $(\mathrm{Kg} * \mathrm{~K})$; and $T_{i}$ is the room temperature.

The relationship between the sensible heat provided by the air-conditioning system to the room and the air output can be expressed as follows [28]: 


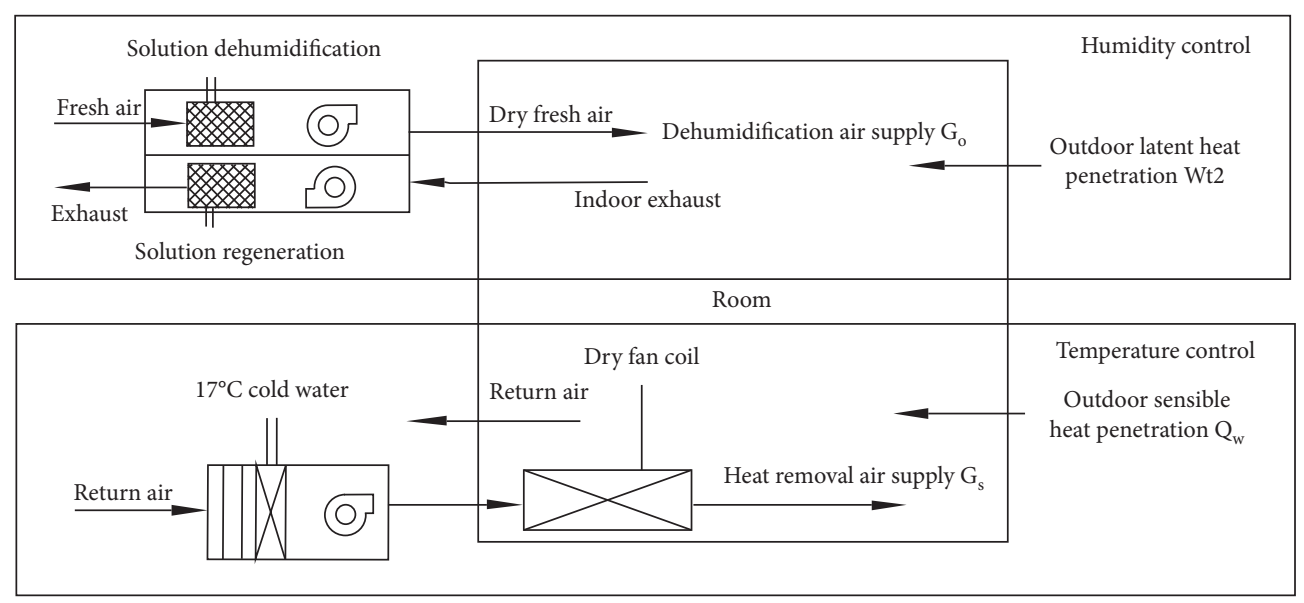

FIgURE 1: Air-conditioning system diagram.

$$
Q_{r}(t)=\rho C_{1} G_{s}(t) T_{s}(t),
$$

where $G_{s}(t)$ is the volume of air supplied, $\mathrm{m}^{3}$, and $T_{s}(t)$ is the air temperature of the sensible heat dry fan coil, ${ }^{\circ} \mathrm{C}$.

For rooms that use temperature and humidity as variables to control the air-conditioning system independently, the main factors that affect the indoor temperature response are listed as follows: sensible heat flowing out of the room and heat dissipation of the room [36]. Heat dissipation of the room includes the following parts: (1) instantaneous sensible cooling load due to the indoor and outdoor temperature difference and direct heat dissipation from the indoor heat source. (2) Heat dissipation caused by the radiation of sunlight through the window.

Heat dissipation of the room $Q_{w}(t)$ is expressed as follows [37]:

$$
Q_{w}(t)=\frac{F \lambda}{\delta}\left(T_{o}(t)-T_{i}(t)\right)+\alpha_{i}\left(T_{o}(t)-T_{i}(t)\right)+\sigma,
$$

where $F$ is the wall area, $\mathrm{m}^{2} ; \lambda$ is the thermal conductivity of the wall material layer; $\delta$ is the thickness of the wall material layer, $\mathrm{m} ; T_{o}$ is the outdoor ambient temperature; $\alpha_{i}$ is the heat transfer coefficient of composite heat transfer surface of the inner wall of the glass window; and $\sigma$ is the heat generated by the solar radiation of the glass window in the room.

The sensible heat flowing out of the room is primarily the heat taken away by return air. Given that the office building is assumed to be a closed-loop system, the return air volume can be calculated according to the supply air volume of the temperature control system as follows [29]:

$$
Q_{d}(t)=\rho C_{1} G_{s}(t) T_{i}(t) .
$$

Substituting (2)-(5) into (1),

$$
\begin{aligned}
\rho V C_{1} \dot{T}_{i}= & \rho C_{1} G_{s}(t) T_{s}(t)+\frac{F \lambda}{\delta}\left(T_{o}(t)-T_{i}(t)\right) \\
& +\alpha_{i}\left(T_{o}(t)-T_{i}(t)\right)+\sigma-\rho C_{1} G_{s}(t) T_{i}(t) .
\end{aligned}
$$

2.2. Dynamic Response of Humidity. The dehumidification system of the air conditioner with independent control of temperature and humidity adopts the full fresh air system. The humidity control system bears all the latent heat load of the building by sending dry fresh air with moisture content lower than the interior designed state. Under the assumptions that the office building is a closed-loop system and the pressure in the building remains unchanged, mass conservation of air humidity can be calculated as follows [38]:

$$
M_{n} \dot{d}_{n}(t)=G_{o}(t)\left(d_{s}(t)-d_{n}(t)\right)+W_{h}(t),
$$

where $M_{n}$ is the total mass of air in the building, $\mathrm{g} ; d_{n}(t)$ is the moisture content of the air in the building, $\mathrm{g} / \mathrm{kg} ; d_{s}(t)$ is the moisture content of the air supply of the air conditioner, $\mathrm{g} / \mathrm{kg} ; G_{o}(t)$ is the exhaust volume of the dehumidification system, $\mathrm{g} / \mathrm{h}$; and $W_{h}(t)$ is the indoor humidity load, $\mathrm{g} / \mathrm{h}$.

Hence, determining the total indoor wet load $W_{h}$ is important. The building's moisture production primarily comes from people indoors, water surface, plants, and the amount of moisture from infiltrating air [39]. Given that this paper considers an office place, the main indoor moisture load involves the number of people that dissipates moisture and the amount of moisture dissipated by fresh air penetration [40].

The wet load of personnel in the office building based on the adults is calculated as follows [32]:

$$
W_{t 1}(t)=0.278 n \varnothing g * 10^{-6}
$$

where $n$ is the number of indoor personnel, $\varnothing$ is the personnel cluster coefficient, and $g$ is the amount of moisture dissipated by the adults, $\mathrm{g} / \mathrm{h}$.

Conventional air-conditioning systems only considered the wet load caused by fresh air penetration in winter but ignored the insignificant wet load generated by fresh air penetration in summer. By comparison, dry air is responsible for dehumidification in air-conditioning systems with independent temperature and humidity control although its dehumidification capacity is limited. Therefore, large humidity load caused by outdoor fresh air penetration 
must be considered. The wet load due to fresh air penetration can be calculated as follows [33]:

$$
W_{t 2}(t)=L \rho\left(d_{o}(t)-d_{n}(t)\right),
$$

where $L$ is the infiltration air volume $\mathrm{m}^{3}$ and $d_{o}$ is the outdoor air moisture content.

Substituting (8) and (9) into (7) leads to

$$
\begin{aligned}
M_{n} \dot{d}_{n}(t)= & G_{o}(t)\left(d_{s}(t)-d_{n}(t)\right) \\
& +0.278 n \varnothing g * 10^{-6}+L \rho\left(d_{o}(t)-d_{n}(t)\right) .
\end{aligned}
$$

2.3. Estimate of Indoor $\mathrm{CO}_{2}$ Concentration. The latent heat control system in the air conditioner with independent control of temperature and humidity uses full fresh air input to ensure that the predicted air concentration in the office space will remain fresh. The relationship between the indoor concentration and the air volume of the air conditioner in the absence of people is expressed as follows:

$$
V \dot{C}=C_{\text {out }} V_{v}(t)+Q_{p}-\left(V_{v}(t)+L\right) C,
$$

where $C$ is the indoor $\mathrm{CO}_{2}$ concentration; $Q_{p}$ is the pollutant emission rate; and $V_{v}$ is the room mechanical ventilation $\left(\mathrm{m}^{3} / \mathrm{h}\right)$. Given that the room is considered a closed-loop system, the mechanical ventilation volume is equal to the input air volume of the latent heat control system, that is, $V_{v}(t)=\left(G_{o}(t) / \rho\right)$.

According to the actual situation of the office building, the amount of indoor $\mathrm{CO}_{2}$ concentration is calculated from 8 am to $6 \mathrm{pm}$. Indoor persons are in the normal office state. The extremely light activity state estimates that the average amount of $\mathrm{CO}_{2}$ concentration is $18 \mathrm{~L} /($ person $* \mathrm{~h}$ ).

Therefore, the indoor $\mathrm{CO}_{2}$ concentration prediction model is expressed as follows:

$$
V \dot{C}=C_{\text {out }} V_{v}(t)+Q_{p}+18 n-\left(V_{v}(t)+L\right) C,
$$

where $n$ is the number of people in the office.

\section{Design of Sliding Mode Controller}

Define that $x_{1}=T_{s}-T_{i}, u_{1}=G_{s}\left(T_{s}-T_{i}\right)=G_{s} x_{1}$, and $x_{2}=d_{s}-d_{n}, u_{2}=G_{o}\left(d_{s}-d_{n}\right)$ are the state variables. Given that the supplied air temperature $T_{s}$ and the supplied air moisture content $d_{s}$ are unchanged, $T_{i}=-\dot{x}_{1}$ and $d_{n}=-\dot{x}_{2}$.

3.1. Temperature Controller. The state equation of the temperature response in the room can be expressed as follows:

$$
\rho V C_{1} \dot{x_{1}}=-\rho C_{1} u_{1}-\frac{F \lambda}{\delta}\left(T_{o}-T_{s}+x_{1}\right)-\alpha_{i}\left(T_{o}-T_{s}+x_{1}\right)-\sigma .
$$

Define $x_{d 1}$ as the error between the supplied air temperature of the terminal device and the ideal indoor temperature $T_{d}$; that is, if $x_{d 1}=T_{s}-T_{d}$, then $e_{1}=x_{1}-x_{d 1}$.
The integral sliding surface can reduce the steady-state error of the system, weaken the chattering, and enhance the stability of the temperature controller. Therefore, the integral sliding mode surface function is defined as follows:

$$
\text { If } s=e_{1}+k \int e_{1} \mathrm{~d} t \text {, then }
$$

$$
\begin{aligned}
\dot{s}=\dot{e}_{1}+k e_{1}= & \dot{x}_{1}+k e_{1}=-\frac{u_{1}}{V}-\frac{\left(F \lambda+\alpha_{i} \delta\right) x_{1}}{\rho V C_{1} \delta} \\
& -\frac{\left(F \lambda+\alpha_{i} \delta\right)\left(T_{o}-T_{s}\right)}{\rho V C_{1} \delta}-\frac{\sigma}{\rho V C_{1}}+k e .
\end{aligned}
$$

When the system state trajectories reached onto the sliding surface, $\dot{s}=0$ is satisfied and the sliding mode accessibility condition ensures that the motion point at any position in the state space reaches the switching surface within a limited time and the trajectory of approaching movement is unlimited. Therefore, the approach law can effectively improve the dynamic quality of the approach movement. Therefore, the following reaching law of the power function is selected:

$$
\dot{s}=-k_{1}|s|^{a} \operatorname{sgn}(s), \quad k>0,0<a<1 .
$$

Given that $\lim _{s \longrightarrow 0^{+}} \dot{s}=\lim _{s \longrightarrow 0^{+}}=k_{1}|s|^{a} \operatorname{sgn}(s)<0$ and $\lim _{s \longrightarrow 0^{-}} \dot{s}=\lim _{s \longrightarrow 0^{-}}=k_{1}|s|^{a} \operatorname{sgn}(s)>0$, the power reaching law guarantees the existence of the sliding mode and the global arrival condition.

Therefore, we can obtain the following formula based on (14) and (15):

$$
\begin{aligned}
\dot{s}= & -\frac{u_{1}}{V}-\frac{\left(F \lambda+\alpha_{i} \delta\right) x_{1}}{\rho V C_{1} \delta}-\frac{\left(F \lambda+\alpha_{i} \delta\right)\left(T_{o}-T_{s}\right)}{\rho V C_{1} \delta} \\
& -\frac{\sigma}{\rho V C_{1}}+k e_{1}=-k_{1}|s|^{a} \operatorname{sgn}(s) .
\end{aligned}
$$

Thus, the following sliding mode controller based on the power reaching law is obtained:

$$
\begin{aligned}
u_{1}= & -\frac{\left(F \lambda+\alpha_{i} \delta\right) x_{1}}{\rho V C_{1} \delta}-\frac{\left(F \lambda+\alpha_{i} \delta\right)\left(T_{o}-T_{s}\right)}{\rho V C_{1} \delta} \\
& -\frac{\sigma}{\rho C_{1}}+\left(k e_{1}+k_{1}|s|^{a} \operatorname{sgn}(s)\right) V .
\end{aligned}
$$

Define the following Lyapunov function, $V(s)=\left(1 / 2 s^{2}\right)$ :

$$
\begin{aligned}
V \dot{(s)}= & \dot{s s}=\left(\dot{e}+k e_{1}\right) s \\
= & \left(-\frac{u_{1}}{V}-\frac{\left(F \lambda+\alpha_{i} \delta\right) x_{1}}{\rho V C_{1} \delta}-\frac{\left(F \lambda+\alpha_{i} \delta\right)\left(T_{o}-T_{s}\right)}{\rho V C_{1} \delta}\right. \\
& \left.-\frac{\sigma}{\rho C_{1}}+k e_{1}\right) s .
\end{aligned}
$$

Substituting that (17) is substituted into the available $V(s)=-k_{1}|s|^{a} \operatorname{sgn}(s) s$ since $k_{1}>0$ and $0<a<1$, it obtains $V(s)<0$. Therefore, the dehumidification system is stable. 
3.2. Humidity Controller. Equation (10) presents that the state equation of the temperature response in the room can be expressed as follows:

$$
M_{n} \dot{x}_{2}=-u_{2}-0.278 n \varnothing g * 10^{-6}-L \rho\left(d_{o}-d_{s}+x_{2}\right) \text {. }
$$

Define $x_{d 2}$ as the error between the supplied air humidity of the latent heat removal terminal device and the ideal indoor humidity $d_{l}$; that is, $x_{d 2}=d_{s}-d_{l}$ and $e_{2}=x_{2}-x_{d 2}$.

Selecting sliding surface function which is $s=e_{2}+k_{3} \int e_{2} \mathrm{~d} t$, then

$$
\begin{aligned}
\dot{s} & =\dot{e}_{2}+k_{3} e_{2} \\
& =-\frac{-u_{2}-0.278 n \varnothing g * 10^{-6}-L \rho\left(d_{o}-d_{s}+x_{2}\right)}{M_{n}}+k_{3} e_{2} .
\end{aligned}
$$

The selected exponential approach law is

$$
\dot{s}=-k_{2} s-\varepsilon \operatorname{sgn}(s), \quad k_{2}>0, \varepsilon>0 .
$$

If $\quad \lim \dot{s}=\lim =-k_{2} s-\varepsilon \operatorname{sgn}(s)<0 \quad$ and $\lim \dot{s}=\lim ^{s \longrightarrow 0^{+}}=-k_{2} s \stackrel{s \longrightarrow 0^{+}}{0^{+}}(s)>0$, then power reaching $\mathrm{faw} 0^{-}$achieves $\overrightarrow{\mathrm{C}}^{-}$the condition of sliding motion and global reachability.

Furthermore we can obtain the following formula based on (20) and (21):

$$
\begin{aligned}
\dot{s} & =\frac{-u_{2}-0.278 n \varnothing g * 10^{-6}-L \rho\left(d_{o}-d_{s}+x_{2}\right)}{M_{n}}+k_{3} e_{2} \\
& =-k_{2} s-\varepsilon \operatorname{sgn}(s) .
\end{aligned}
$$

Hence, $\quad u_{2}=-M_{n}\left(-k_{2} s-\varepsilon s g n \quad(s)-k_{3} e_{2}\right)-L \rho\left(d_{o}-\right.$ $\left.d_{s}+x_{2}\right)-0.278 n \varnothing g * 10^{-6}$.

Select the following Lyapunov function: $V(s)=\left(1 / 2 s^{2}\right)$.

Then, $V(s)=\dot{s s}=\left(\left(-u_{2}-0.278 n \varnothing g * 10^{-6}-L \rho\left(d_{o}-\right.\right.\right.$ $\left.\left.\left.d_{s}+x_{2}\right) / M_{n}\right)+k_{3} e_{2}\right) s=s\left(-k_{2} s-\varepsilon \operatorname{sgn}(s)\right)=-k_{2} s^{2}-s \varepsilon s g n$ $(s)$.

Because $k_{2}>0, \varepsilon>0, V(s)<0$, the system is stable.

\section{Design of Fuzzy Sliding Mode Controller}

In this paper, approach laws $\dot{s}=-k_{1}|s|^{a} \operatorname{sgn}(s)$ and $\dot{s}=-k_{2} s-\varepsilon \operatorname{sgn}(s)$ are selected, in which $k_{1}, k_{2}$, and $\varepsilon$ are appropriate parameters to be selected to ensure that the system state trajectories reach to sliding surface rapidly and suppress chattering. Thus, this paper proposes fuzzy SMC based on reaching laws. The use of fuzzy control instead of traditional control solves the chattering problem of the airconditioning system while improving the dynamic quality of the system and ensuring the good robustness of the system.

4.1. Parameter Fuzzification. This study designs a two-dimensional fuzzy controller to meet the requirements for a stable air-conditioning system under the conditions of temperature parameter changes and interference effects during the operation of the air conditioner. The input signal of fuzzy law is the temperature error $e$ and its derivative $\left(d_{e} / d_{t}\right)$. The output signal is the reaching law parameters $\varepsilon$, $k_{1}$, and $k_{2}$. The fuzzy subsets of input and output variables are $\{\mathrm{NB}, \mathrm{NM}, \mathrm{NS}, \mathrm{ZO}, \mathrm{PS}, \mathrm{PM}, \mathrm{PB}\}$ and quantified in the $(-1$, 1) area. The membership function is selected as a symmetric triangular function, and each value of the fuzzy subset has the same range width [41].

4.2. Fuzzy Rules. According to the principle of SMC, the parameters of the reaching law $k_{1}, k_{2}$, and $\varepsilon$ determine the fuzzy rules, as shown in Tables $1-3$, respectively.

4.3. Fuzzy Reasoning. This paper uses the center of gravity method to complete deblurring. The output result after deblurring is presented as follows:

$$
x_{0}=\frac{\sum_{i=1}^{n} x_{i} u_{c}\left(x_{i}\right)}{\sum_{i=1}^{n} x_{i}},
$$

where $x_{0}$ is the output result after defuzzification, $x_{i}$ is the output variable, and $u_{c}\left(x_{i}\right)$ is the membership function corresponding to $x_{i}$.

\section{Simulation Analysis}

This study uses MATLAB/Simulink to establish the simulation model of the central air-conditioning system. Fuzzy sliding mode control and traditional PID control methods are used to compare and verify the correctness and feasibility of the proposed strategy.

Assuming that the room has a length, width, and height of 16,10 , and $4 \mathrm{~m}$, respectively, the indoor air density, indoor air specific heat capacity, coefficient of thermal conductivity of wall materials, and thickness of the wall material are $\rho=1.204 \mathrm{~kg} / \mathrm{m}^{3}, C=1.003 \mathrm{~J} /(\mathrm{Kg} * \mathrm{~K}), \lambda=0.58 \mathrm{~W} /(\mathrm{mK})$, and $\delta=0.5 \mathrm{~m}$, respectively. Figure 2 illustrates the heat generated by sunlight radiating through the glass in the room.

The indoor temperature is set to $25^{\circ} \mathrm{C}$, and the input of outdoor temperature and humidity changes according to the data collected in Suzhou in July, as shown in Figures 3 and 4 .

Assuming that the initial indoor ambient temperature is $26^{\circ} \mathrm{C}$ and the moisture content is $13 \mathrm{~g} / \mathrm{kg}$, the enthalpy chart demonstrates that the air moisture content is $12 \mathrm{~g} / \mathrm{kg}$ when the temperature is set to $25^{\circ} \mathrm{C}$ and the optimum indoor relative humidity is $60 \%$. Therefore, the ideal air moisture content is $12 \mathrm{~g} / \mathrm{kg}$.

The comparison of indoor temperature and humidity responses under the sliding mode and the PID control strategies are illustrated in Figures 5 and 6, respectively.

The air volume input of indoor temperature and humidity control under the sliding mode and PID control strategies is compared and illustrated in Figures 7 and 8, respectively.

Figures 5-8 demonstrate that the air conditioner system with independent control of temperature and humidity using the fuzzy SMC strategy can achieve the set temperature 
Table 1: Fuzzy rule with parameter $k_{1}$.

\begin{tabular}{llccccc}
\hline$e_{1}$ & & & $e_{1}$ & & \\
& NB & NM & NS & ZO & PS & PM \\
\hline NB & PB & PB & PM & PS & PS & ZO \\
NM & PB & PB & PM & PS & PS & ZO \\
NS & PM & PM & PM & ZO & ZO & NS \\
ZO & PM & PM & PS & NS & NS & NM \\
PS & PS & PS & ZO & NS & NS & NM \\
PM & PS & ZO & NS & NM & NM \\
PB & ZO & ZO & NM & NM & NB \\
& & & & & NB \\
\hline
\end{tabular}

Table 2: Fuzzy rule with parameter $k_{2}$.

\begin{tabular}{lllllll}
\hline$e_{2}$ & & & $e_{2}$ & & \\
& NB & NM & NS & ZO & PS & PM \\
\hline NB & NB & NB & NM & NM & NS & ZO \\
NM & NB & NB & NM & NS & NS & ZO \\
NS & NB & NM & NS & NS & ZO & PS \\
ZO & NM & NM & NS & ZO & PS & PM \\
PS & NM & NS & ZO & PS & PS & PM \\
PM & ZO & ZO & PS & PS & PB \\
PB & ZO & ZO & PS & PM & PB \\
\hline
\end{tabular}

TABle 3: Fuzzy rule with parameter $\varepsilon$.

\begin{tabular}{llccccc}
\hline$e_{2}$ & & & $e_{2}$ & & \\
& NB & NM & NS & ZO & PS & PB \\
\hline NB & NB & NB & NM & NM & NS & ZO \\
NM & NB & NB & NM & NS & NS & ZO \\
NS & NB & NM & NS & NS & ZO & PS \\
ZO & NM & NS & NS & ZO & PS & PM \\
PS & NM & NS & ZO & PS & PM & PM \\
PM & NS & ZO & PS & PM & PB \\
PB & ZO & ZO & PS & PM & PB \\
\hline & & & & & PB \\
\hline
\end{tabular}

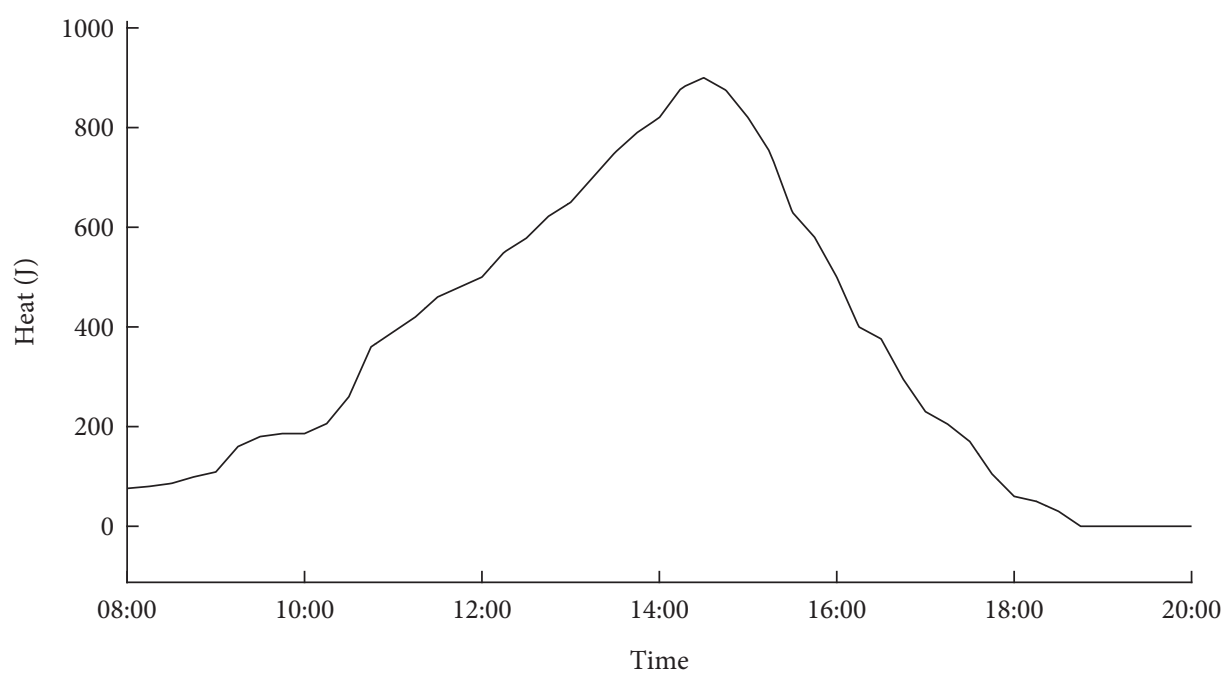

Figure 2: Heat from solar radiation. 


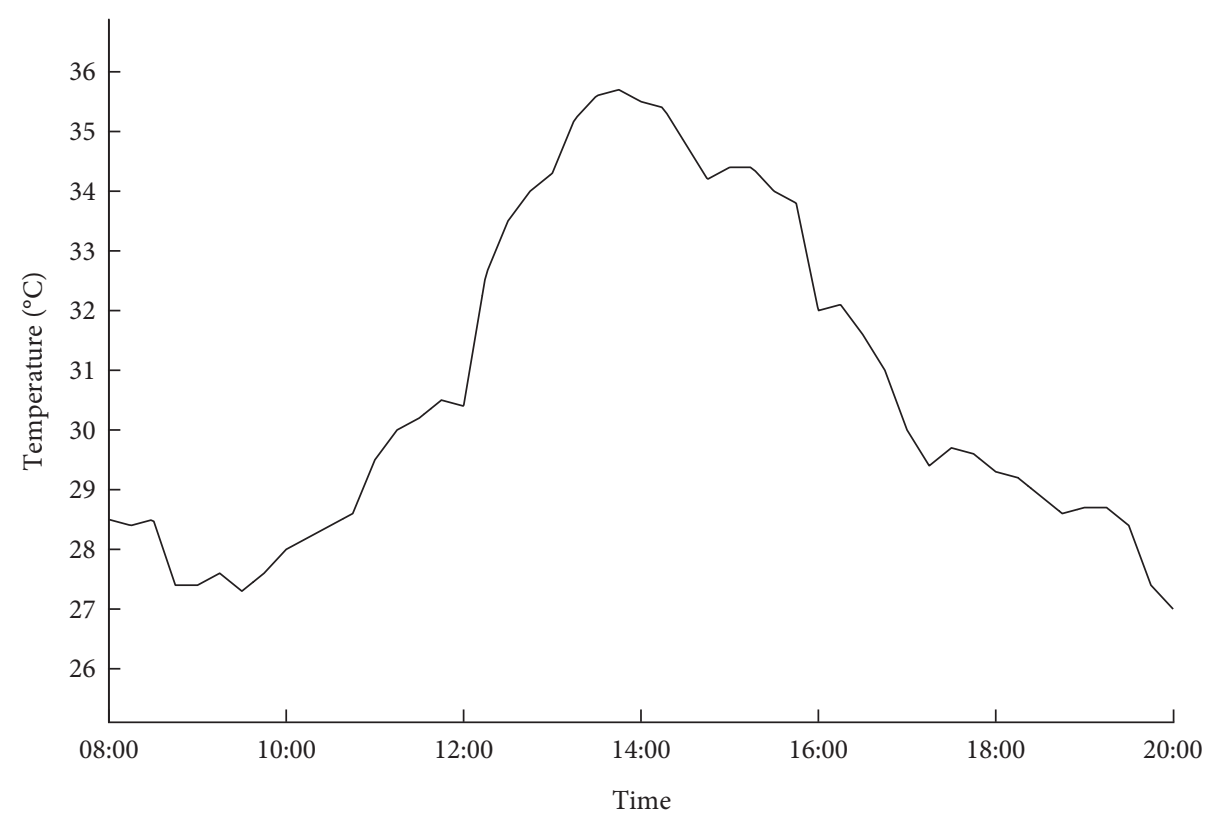

FIgURE 3: Outdoor temperature change.

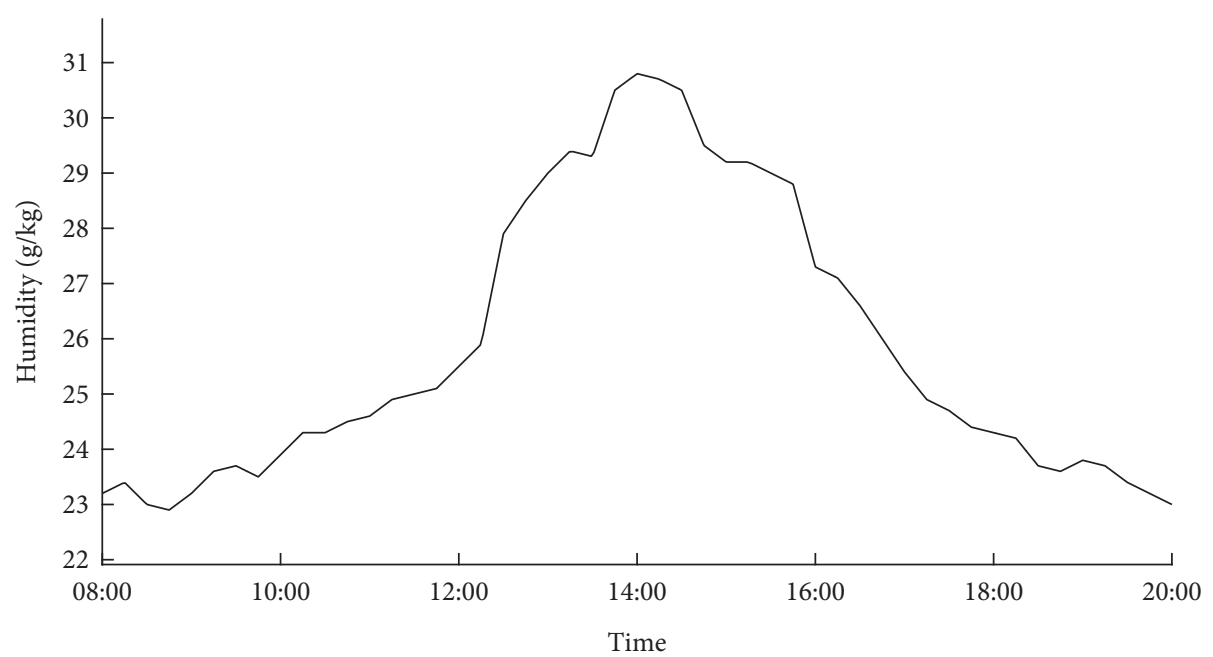

FIGURE 4: Outdoor humidity change.

and humidity faster when the input air volume is only slightly different compared with the PID control. Meanwhile, it can be seen in Figures 5 and 6 that, compared with the air-conditioning system under PID control, the fuzzy sliding mode control strategy has minimal vibration at the preset humidity and temperature. From the data derived from the figure, it can be seen that the indoor temperature reaches the expected temperature time under fuzzy sliding mode control, fuzzy PID, and PID strategies: $7.668 \mathrm{~min}$, $9.630 \mathrm{~min}$, and $11.256 \mathrm{~min}$, and the temperature overshoots are $0.0939,0.3095$, and 0.3789 . The time for indoor humidity to reach the expected humidity is $11.256 \mathrm{~min}, 17.148 \mathrm{~min}$, and $18.954 \mathrm{~min}$. The humidity overshoot is $0.1145,0.2284$, and 0.3272 .
So, you can get the following result.

Theorem 1. The temperature error of the fuzzy sliding mode control strategy is only $30 \%$ and $24 \%$ of the other two methods.

Theorem 2. The humidity error of the fuzzy sliding mode control strategy is 50\% and 35\% of the other two methods.

Theorem 3. Compared with the traditional PID control technique, the higher accuracy of the SMC strategy ensures that the indoor environment is maintained at the desired level and meets the comfort requirements of the human body. 


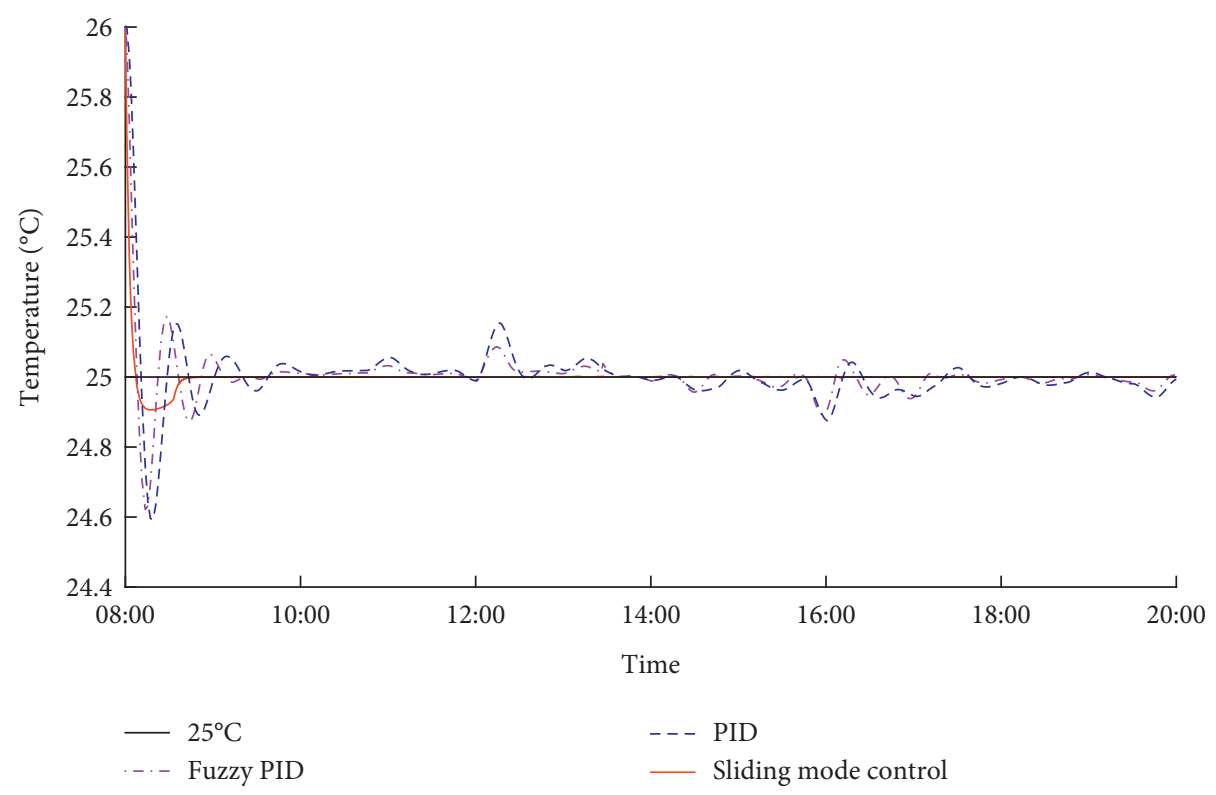

FIgURE 5: Indoor temperature response.

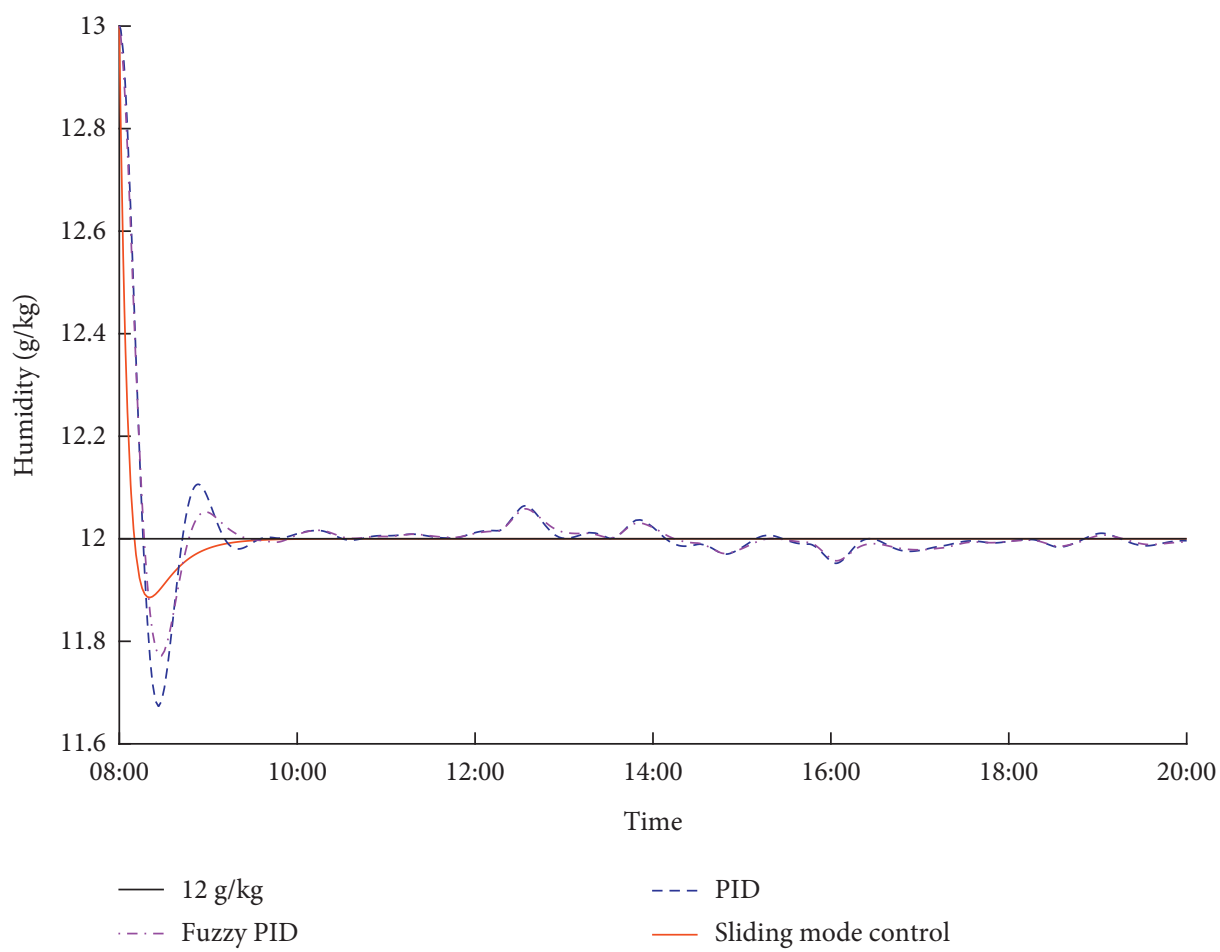

FIGURE 6: Indoor humidity response.

Under the above circumstances, assuming that 10 people are inside the office, the fresh air input can be used to estimate the $\mathrm{CO}_{2}$ concentration in the indoor air within a day with the office $\mathrm{CO}_{2}$ concentration accounting for $0.045 \%$ of the air at 8 : 00. The simulation results are illustrated in Figure 9.
Figure 9 shows that the air conditioner with independent control of temperature and humidity using the fuzzy SMC can ensure a maximum indoor $\mathrm{CO}_{2}$ concentration of $0.1 \%$ [42], which belongs to fresh air and meets the requirements of human comfort. 


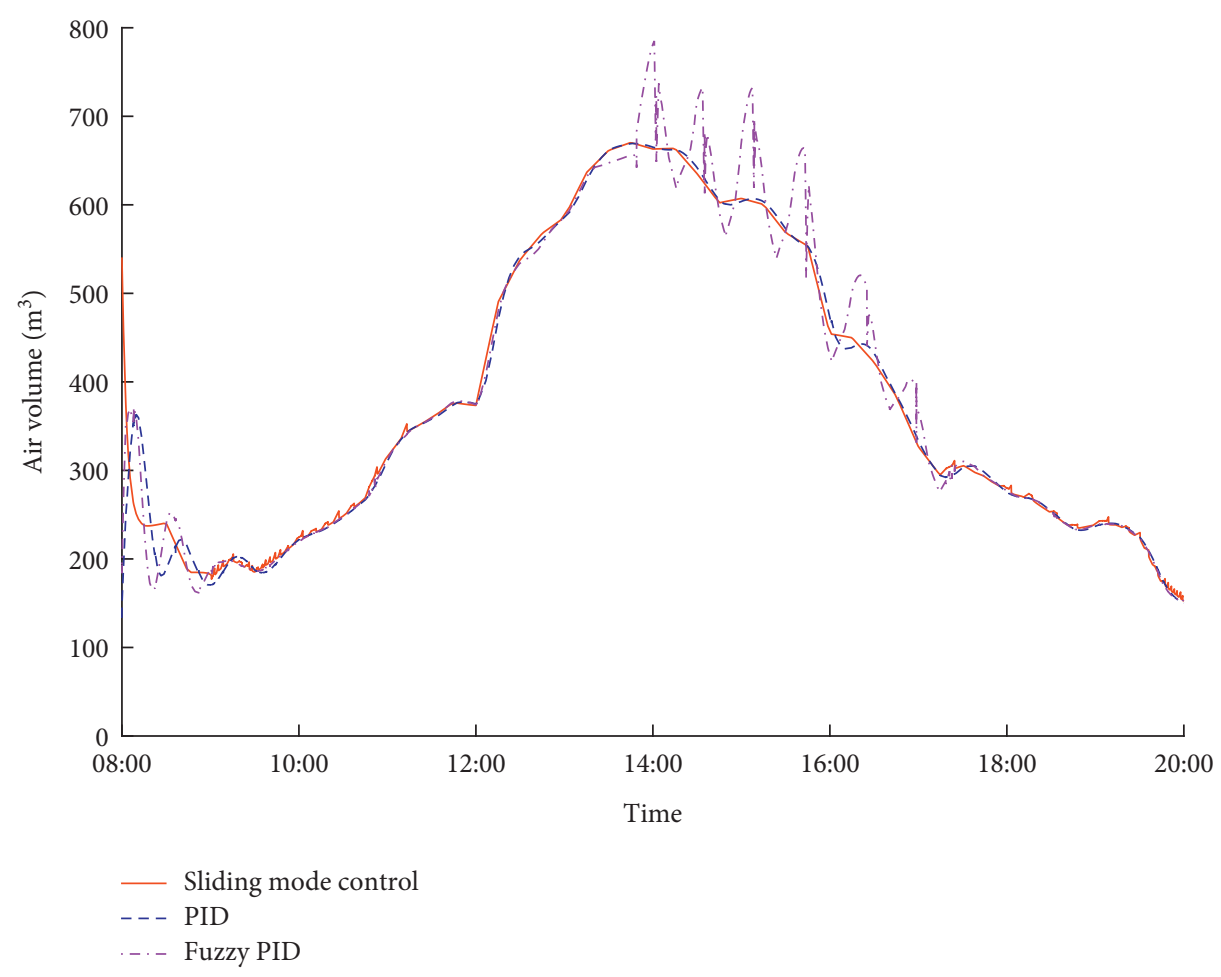

Figure 7: Temperature control input air volume.

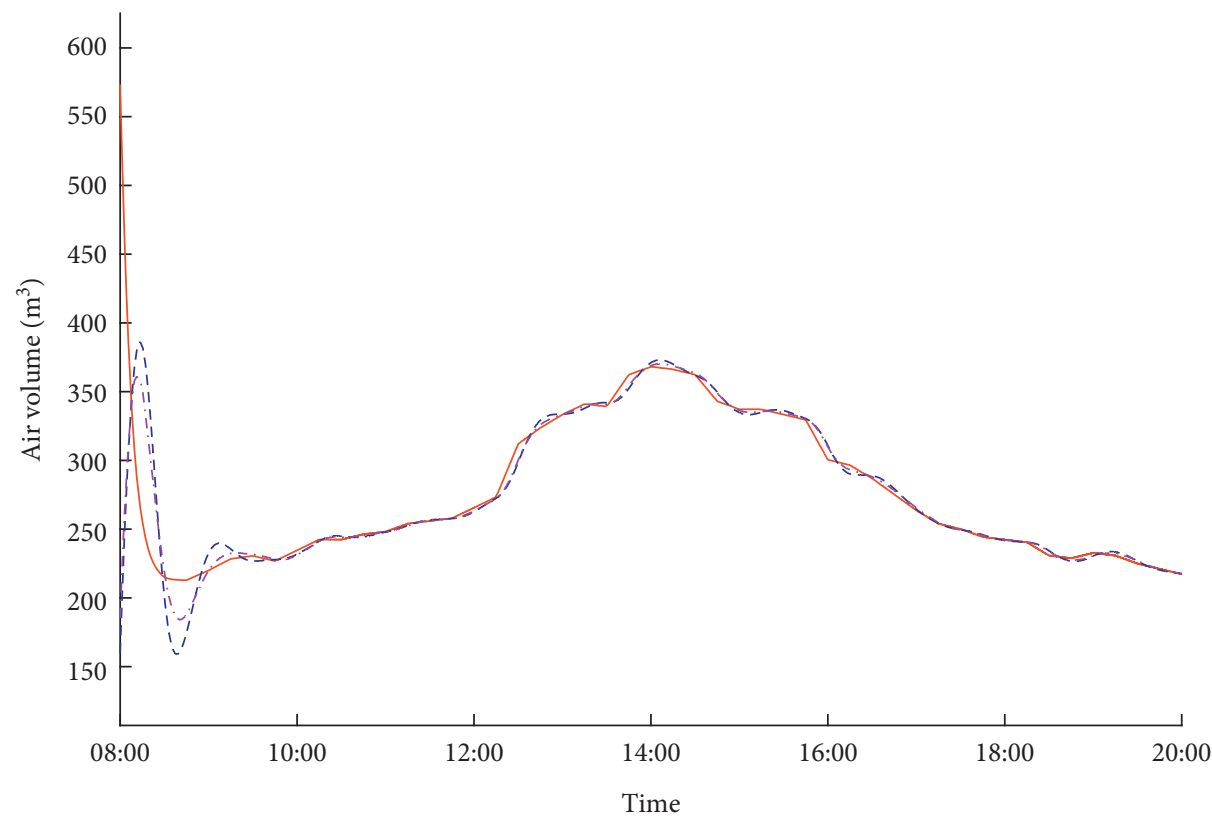

_ Sliding mode control

- - PID

-..- SYS 29

FIGURE 8: Humidity control input air volume. 


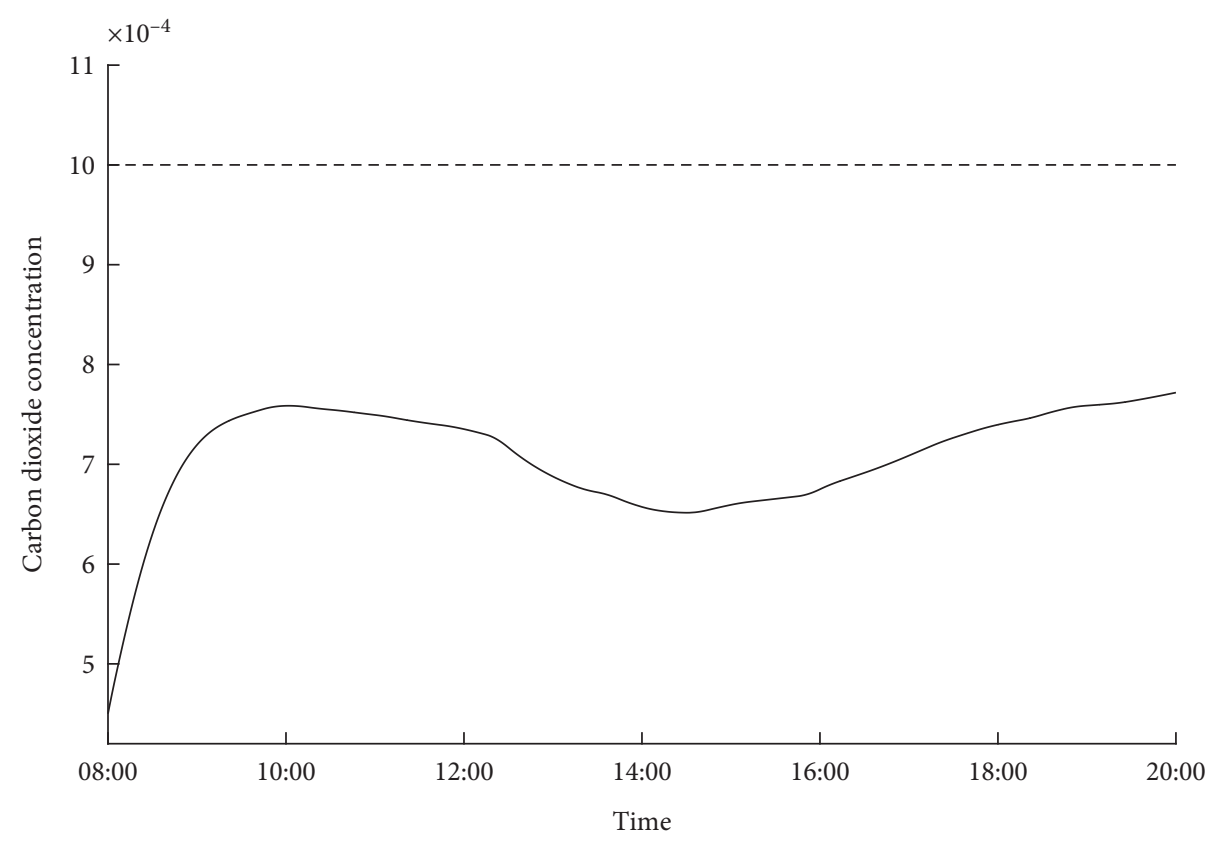

FIgURE 9: $\mathrm{CO}_{2}$ content assessment.

\section{Conclusion}

This paper proposes a fuzzy sliding mode approach for the independent control of temperature and humidity in airconditioning systems. By analyzing the indoor environmental effect, mathematical models for room temperature, humidity, and $\mathrm{CO}_{2}$ concentration are developed. Compared with the traditional PID method, the simulation results show that the fuzzy-rules-based SMC achieves better dynamic performance. However, the proposed method is only applicable to the temperature- and humidity-independent control air-conditioning system in solution dehumidification mode. If the rotor dehumidification is used, it may lead to a large deviation in temperature control due to the coupling of heat and humidity. It is expected that the following research can overcome the temperature and humidity coupling of the air conditioner happening. The results of this study can provide practical guidance for engineering applications.

\section{Data Availability}

The data of outdoor temperature and humidity changes in this paper are measured by the author. The data used to support the findings of this study are available from the corresponding author upon request.

\section{Conflicts of Interest}

The authors declare that they have no conflicts of interest.

\section{Acknowledgments}

This work was supported in part by the NSFC under Grant nos. 61803279, 11871366, and 61672371, the Qing Lan Project of Jiangsu, the China Postdoctoral Science
Foundation under Grant no. 2020M671596, the Open Project Funding from Anhui Province Key Laboratory of Intelligent Building and Building Energy Saving, Anhui Jianzhu University, under Grant no. IBBE2018KX02ZD, the Natural Science Foundation of the Jiangsu Higher Education Institutions of China under Grant no. 18KJB460026, the Suzhou Science and Technology Foundation under Grant no. SYG201813, and the Jiangsu Province Graduate Practice Innovation Program under Grant no. SJCX19_0844.

\section{References}

[1] M. Castilla, J. D. Álvarez, J. E. Normey-Rico, and F. Rodríguez, "Thermal comfort control using a non-linear MPC strategy: a real case of study in a bioclimatic building," Journal of Process Control, vol. 24, no. 6, pp. 703-713, 2014.

[2] R. M. Lazzarin and F. Castellotti, "A new heat pump desiccant dehumidifier for supermarket application," Energy and Buildings, vol. 39, no. 1, pp. 59-65, 2007.

[3] X. L. Hao, G. Q. Zhang, Y. M. Chen, S. Zou, and D. J. Moschandreas, "A combined system of chilled ceiling, displacement ventilation and desiccant dehumidification," Building and Environment, vol. 42, no. 9, pp. 3298-3308, 2007.

[4] P. Zhang, S. Cao, L. Wu, and J. Lv, "Status and development of temperature and humidity independent control air conditioning system," Shanghai Energy Saving, vol. 10, pp. 583-587, 2017.

[5] A. Abdel Hamid, S. F. Rezeka, and A. M. Saleh, "Fuzzy logic control of air-conditioning system in residential buildings," Alexandria Engineering Journal, vol. 54, no. 3, pp. 395-403, 2015.

[6] S. A. Shahnawaz, M. M. Shah, H. Novia, and H. Abd Rahman, "Fuzzy logic based energy saving technique for a central air conditioning system," Energy and Buildings, vol. 32, no. 7, pp. 1222-1234, 2007.

[7] G. Li, "Fuzzy PID research on the temperature control system of central air conditioning based on genetic algorithms," 
Information Technology Journal, vol. 12, no. 24, pp. 83138317, 2013.

[8] S. Soyguder, M. Karakose, and H. Alli, "Design and simulation of self-tuning PID-type fuzzy adaptive control for an expert HVAC system," Expert Systems with Applications, vol. 36, no. 3, pp. 4566-4573, 2009.

[9] F. Ascione, N. Bianco, C. De Stasio, G. M. Mauro, and G. P. Vanoli, "Simulation-based model predictive control by the multi-objective optimization of building energy performance and thermal comfort," Energy and Buildings, vol. 111, pp. 131-144, 2016.

[10] T. Yang, N. Sun, H. Chen, and Y. Fang, "Neural networkbased adaptive antiswing control of an underactuated shipmounted crane with roll motions and input dead zones," IEEE Transactions on Neural Networks and Learning Systems, vol. 31, no. 3, pp. 901-914, 2020.

[11] N. Sun, D. Liang, Y. Wu, Y. Chen, Y. Qin, and Y. Fang, "Adaptive control for pneumatic artifificial muscle systems with parametric uncertainties and unidirectional input constraints," IEEE Transactions on Industrial Informatics, vol. 16, no. 2, pp. 969-979, 2019.

[12] W. Hu, Q. Zhu, and H. R. Karimi, "Some improved Razumikhin stability criteria for impulsive stochastic delay differential systems," IEEE Transactions on Automatic Control, vol. 64, no. 12, pp. 5207-5213, 2019.

[13] H. Wang and Q. Zhu, "Global stabilization of stochastic nonlinear systems via \$C1\$ and \$C\{linfty \}\$ controllers," IEEE Transactions on Automatic Control, vol. 62, no. 11, pp. 5880-5887, 2017.

[14] Q. Zhu and H. Wang, "Output feedback stabilization of stochastic feedforward systems with unknown control coefficients and unknown output function," Automatica, vol. 87, pp. 166-175, 2018.

[15] Q. Zhu, "Stabilization of stochastic nonlinear delay systems with exogenous disturbances and the event-triggered feedback control," IEEE Transactions on Automatic Control, vol. 64, no. 9, pp. 3764-3771, 2019.

[16] H. Wang and Q. Zhu, "Adaptive output feedback control of stochastic nonholonomic systems with nonlinear parameterization," Automatica, vol. 98, pp. 247-255, 2018.

[17] W. Hu and Q. Zhu, "Stability analysis of impulsive stochastic delayed differential systems with unbounded delays," Systems \& Control Letters, vol. 136, Article ID 104606, 2020.

[18] V. Utkin, "Variable structure systems with sliding modes," IEEE Transactions on Automatic Control, vol. 22, no. 2, pp. 212-222, 1977.

[19] J. Liu, Z. Wu, J. Yu, and M. Tan, "Sliding mode fuzzy controlbased path-following control for a dolphin robot," Science China Information Sciences, vol. 61, no. 2, pp. 240-242, 2018.

[20] Z. Zhang, Y. Niu, and H. R. Karimi, "Sliding mode control of interval type-2 fuzzy systems under round-robin scheduling protocol," IEEE Transactions on Systems, Man, and Cybernetics Systems, pp. 1-11, 2019.

[21] W. Qi, G. Zong, and H. R. Karimi, "Finite-time observerbased sliding mode control for quantized semi-Markov switching systems with application," IEEE Transactions on Industrial Informatics, vol. 16, no. 2, pp. 1259-1271, 2020.

[22] Q. P. Ha, Q. H. Nguyen, D. C. Rye, and H. F. Durrant-Whyte, "Fuzzy sliding-mode controllers with applications," IEEE Transactions on Industrial Electronics, vol. 48, no. 1, pp. 38-46, 2001.

[23] B. Jiang, H. R. Karimi, Y. Kao, and C. Gao, "A novel robust fuzzy integral sliding mode control for nonlinear semimarkovian jump T-S fuzzy systems," IEEE Transactions on Fuzzy Systems, vol. 26, no. 6, pp. 3594-3604, 2018.
[24] B. Jiang, H. R. Karimi, Y. Kao, and C. Gao, "Adaptive control of nonlinear semi-Markovian jump T-S fuzzy systems with immeasurable premise variables via sliding mode observer," IEEE Transactions on Cybernetics, vol. 50, no. 2, pp. 810-820, 2018.

[25] H. R. Karimi, “A sliding mode approach to $\mathrm{H} \infty$ synchronization of master-slave time-delay systems with Markovian jumping parameters and nonlinear uncertainties," Journal of the Franklin Institute, vol. 349, no. 4, pp. 1480-1496, 2012.

[26] Y. Wang, H. R. Karimi, H. Shen, Z. Fang, and M. Liu, "Fuzzymodel-based sliding mode control of nonlinear descriptor systems," IEEE Transactions on Cybernetics, vol. 49, no. 9, pp. 3409-3419, 2019.

[27] Z. Wu, B. Jiang, and Y. Kao, "Finite-time $H \propto$ filtering for Itô stochastic Markovian jump systems with distributed timevarying delays based on optimisation algorithm," IET Control Theory \& Applications, vol. 13, no. 5, pp. 702-710, 2019.

[28] Q. Zhu and T. Huang, "Stability analysis for a class of stochastic delay nonlinear systems driven by G-Brownian motion," Systems \& Control Letters, vol. 140, Article ID 104699, 2020.

[29] B. Wang and Q. Zhu, "Stability analysis of semi-Markov switched stochastic systems," Automatica, vol. 94, pp. 72-80, 2018.

[30] B. Wang and Q. Zhu, "Stability analysis of discrete-time semiMarkov jump linear systems," IEEE Transactions on Automatic Control, p. 1, 2020.

[31] X. Jin, H. Ren, and X. Xiao, "Prediction-based online optimal control of outdoor air of multi-zone VAV air conditioning systems," Energy and Buildings, vol. 37, no. 9, pp. 939-944, 2005.

[32] Y. Zhu, X. Jin, Z. Du, and X. Fan, "Control and energy simulation of variable refrigerant flow air conditioning system combined with outdoor air processing unit," Applied Thermal Engineering, vol. 64, no. 2, pp. 385-395, 2014.

[33] X. Xiao, C. Liang, C. Tao, and L. Tong, "Simulation and analysis of a novel cascade double cooling source temperature and humidity independent control air-conditioning system," IOP Conference Series: Earth and Environmental Science, vol. 242, Article ID 022068, 2019.

[34] R. Whalley and A. Abdul-Ameer, "Heating, ventilation and air conditioning system modelling," Building and Environment, vol. 46, no. 3, pp. 643-656, 2011.

[35] P. D. Morosan, R. Bourdais, D. Dumur, and J. Buisson, "Building temperature regulation using a distributed model predictive control," Energy and Buildings, vol. 42, no. 9, pp. 1445-1452, 2010.

[36] A. Afram and F. Janabi-Sharifi, "Theory and applications of HVAC control systems-a review of model predictive control (MPC)," Building and Environment, vol. 72, pp. 343-355, 2014.

[37] G. Ulpiani, S. Summa, and C. Di Perna, "Sunspace coupling with hyper-insulated buildings: investigation of the benefits of heat recovery via controlled mechanical ventilation," Solar Energy, vol. 181, pp. 17-26, 2019.

[38] R. E. L. Diasty, P. Fazio, and I. Budaiwi, "Modelling of indoor air humidity, the dynamic behavior within an enclosure," Energy and Building, vol. 19, pp. 61-63, 1992.

[39] X. Chen, Q. Wang, and J. Srebric, "Model predictive control for indoor thermal comfort and energy optimization using occupant feedback," Energy and Buildings, vol. 102, pp. 357-369, 2015.

[40] S. Yang, M. P. Wan, B. F. Ng et al., "A state-space thermal model incorporating humidity and thermal comfort for 
model predictive control in buildings," Energy and Buildings, vol. 170, pp. 25-39, 2018.

[41] M. Mahmoud, M. A. Mohamed, S. E. Mohamed, F. S. Sabry, and F. G. Fayez, "An adaptive neuro-fuzzy sliding mode controller for MIMO systems with disturbance," Chinese Journal of Chemical Engineering, vol. 25, pp. 463-476, 2017.

[42] GB/T18883-2002: Indoor Air Quality Standards. 